\title{
Economic dan Emission dispatch pada Sistem Kelistrikan 500 kV Jawa-Bali Menggunakan Composite Generation Cost Function dengan Metode Cuckoo Optimization Algorithm
}

\author{
Daya Juang Mahaputra, Rony Seto Wibowo, dan Ardyono Priyadi \\ Jurusan Teknik Elektro, Fakultas Teknologi Industri, Institut Teknologi Sepuluh Nopember (ITS) \\ Jl. Arief Rahman Hakim, Surabaya 60111 Indonesia \\ e-mail: ronyseto@ee.its.ac.id, priyadi@ee.its.ac.id
}

\begin{abstract}
Abstrak - Permintaan daya listrik yang terus bertambah menyebabkan daya listrik yang disuplai oleh pembangkit menjadi lebih besar. Kondisi beban yang harus disuplai pembangkit selalu berubah-ubah tiap waktunya, maka penyaluran energi listrik haruslah sesuai antara energi yang terbangkitkan oleh pembangkit dengan jumlah beban yang harus disuplai untuk memperoleh biaya pembangkitan yang paling ekonomis. Pada Tugas Akhir ini untuk mendapatkan biaya yang ekonomis akan dilakukan optimasi pembangkit sehingga didapatkan nilai pembangkitan yang paling optimal. Pengoptimalan pembangkit bertujuan untuk mendapatkan biaya operasional yang minimum tetapi tetap dapat memenuhi permintaan beban yang ada. Penggunaan generator dengan bahan bakar fosil dapat memberikan efek pencemaran lingkungan akibat emisi sisa dari pembakaran. Proses optimasi akan membuat jumlah bahan bakar yang digunakan dapat diminimalisir sehingga akan mengurangi emisi yang dihasilkan oleh pembangkit.
\end{abstract}

Kata Kunci-Cuckoo Search Algorithm, Composite Generation Cost Function, Economic Dispatch, Emisi.

\section{PENDAHULUAN}

$\mathrm{E}$ NERGI listrik merupakan salah satu kebutuhan yang sangat penting bagi keberlangsungan hidup manusia. Sejak revolusi industri, kebutuhan energi listrik terus meningkat secara tajam. Seiring dengan meningkatnya jumlah populasi dan kesejahteraan manusia menyebabkan kebutuhan energi listrik terus meningkat juga. Permintaan daya listrik yang terus bertambah menyebabkan daya listrik yang disuplai oleh pembangkit menjadi lebih besar. Untuk memenuhi kebutuhan energi manusia dibutuhkan kapasitas pembangkit yang terus meningkat sehingga mengharus menggunakan pembangkit lebih dari satu unit pembangkit yang beroperasi. Jumlah beban yang harus disuplai pembangkit selalu berubah-ubah tiap waktu nya. Oleh karena itu, penyaluran energi listrik haruslah sesuai antara energi yang terbangkitkan oleh pembangkit dengan jumlah beban yang harus disuplai untuk memperoleh biaya pembangkitan yang paling ekonomis. Untuk mendapatkan biaya pembangkitan yang ekonomis, diperlukan suatu mekanisme pembagian pembebanan pada pembangkitan yang biasa disebut dengan Economic Dispatch (ED).

Economic dispatch (ED) merupakan hal penting dalam kontrol dan operasi pada sistem tenaga. Fungsi utama dari ED adalah untuk menjadwalkan pembangkitan dari setiap pembangkit yang beroperasi untuk dapat memenuhi kebutuhan beban pada biaya pembangkitan paling minimal. Untuk mempertahankan life time dari pembangkit dan peralatan pendukung pembangkit, thermal gradient dipertahankan pada batasan aman. Parameter mekanis tersebut diterjemahkan sebagai batas dari laju perubahan daya output atau biasa disebut ramp rate. ED konvensional hanya dapat digunakan untuk satu level beban.

Pembangkit yang ada di pulau Jawa dan Bali kebanyakann merupakan pembangkit thermal yang menggunakan batu bara sebagai bahan bakar utama pembangkitan. Batu bara merupakan energi yang tidak terbarukan dan seiring berjalannya waktu, lama kelamaan jumlah batu bara akan habis. Selain itu, batu bara yang digunakan untuk pembangkit di Jawa dan Bali dikirim dari luar pulau Jawa sehingga harga batu bara juga dipengaruhi oleh harga minyak dunia. Oleh karena itu, perlu dilakukan penghematan dengan cara menentukan pembebanan optimal pada setiap pembangkit.

\section{SISTEM TENAGA LISTRIK}

\section{A. Sistem Pembangkitan}

Generator yang biasa digunakan pada sistem tenaga listrik yaitu generator tiga fasa atau generator sinkron. Generator mengubah energi mekanik menjadi energi listrik menggunakan prinsip induksi elektromagnet [1] bekerja berdasarkan hukum faraday yakni apabila suatu konduktor bergerak pada sebuah medan magnet dan memotong garis garis gaya magnet maka pada ujung penghantar tersebut akan timbulkan ggl (garis gaya listrik). Energi mekanik dapat berasal dari turbin hidrolik pada air terjun, turbin uap, turbin angin, dan lain sebagainya. Pada sistem tenaga, beberapa generator dioperasikan paralel untuk menyuplai beban [2]. Generator pada sistem terkoneksi pada titik titik tertentu yang disebut dengan bus.bertemu di suatu titik pada ketinggian tertentu.

Karakterisktik unit pembangkit meliputi karakteristik inputoutput pembangkit, karakteristik heatrate, dan karakteristik increamental cost rate, karakteristik ini berkaitan dengan biaya 
pembangkitan dari unit pembangkit untuk mencapai nilai yang optimum. Input dari unit pembangkitan berupa bahan bakar yang dinyatakan dalam konsumsi energy (Mbtu/h) atau pembelian bahan bakar $(\$ / \mathrm{h})$. Incremental rate menyatakan hubungan perubahan dari pembangkitan yang dihasilkan dengan konsumsi bahan bakar yang dibutuhkan.

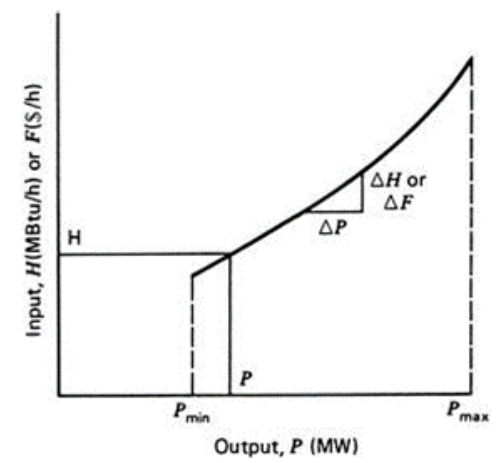

Gambar 1. Kurva Karakteristik Input-Output Unit Pembangkit

\section{B. Sistem Transmisi}

Tujuan dari sistem transmisi yaitu untuk mentransfer energi listrik dari unit unit pembangkit menuju sistem distribusi yang menyuplai beban [2]. Pada sistem tenaga listrik, saluran transmisi akan mengakibatkan losses pada sistem sehingga total tegangan yang dibangkitakan oleh generator harus lebih tinggi dari total beban. Losses pada sistem ini direpresentasikan sebagai matriks B.

\section{Sistem Pembebanan}

Beban pada sistem tenaga dibagi menjadi beberapa kawasan yaitu kawasan industri, komersial, dan residensial. Berdasarkan karakteristik beban pada masing masing kawasan, kebutuhan daya listrik selalu berubah ubah dalam satuan waktu.

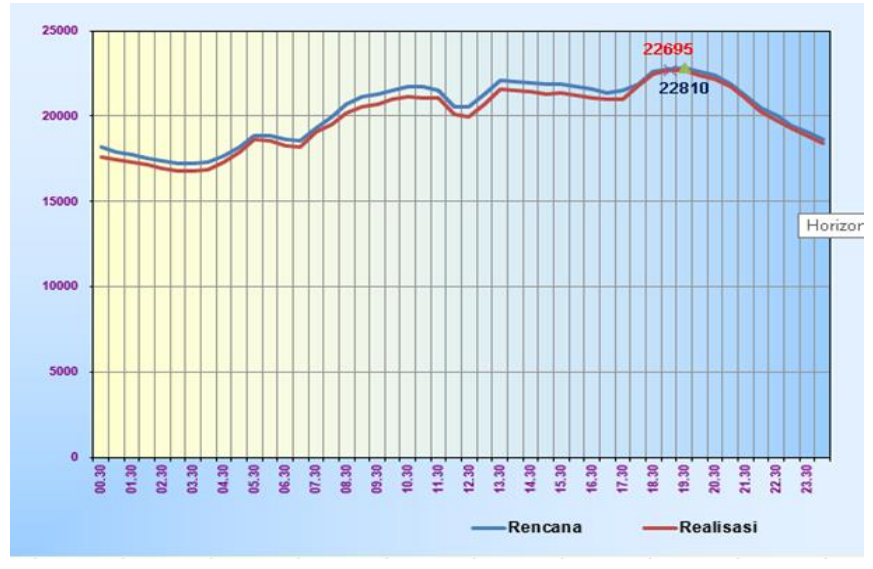

Gambar 2. Profil Beban Harian ${ }^{[3]}$
Pada kurva beban harian, dapat disimpulkan beban pada malam hari cenderung lebih tinggi dibandingkan beban pada siang hari. Permintaan daya minimal yang berlangsung sepanjang hari disebut dengan beban dasar. Sedangkan permintaan daya maksimum yang hanya berlangsung beberapa jam disebut dengan beban puncak. Beban antara beban dasar dan beban puncak disebut beban menengah $[2,4]$.

\section{COMPOSITE GENERATION COST FUNCTION}

Sebuah teknik yang berguna untuk memudahkan prosedur suplai bahan bakar adalah dengan membuat kurva komposit biaya produksi generator. Prosedur sederhana yang dapat dilakukan untuk mendapatkan $\mathrm{Fs}(\mathrm{Ps})$ adalah dengan melakukan iterasi lambda secara bertahap dari $\lambda$ min hinggan $\lambda \max$, dimana

$$
\begin{aligned}
\lambda^{\text {nin }} & =\min \left(\frac{d F_{\mathrm{i}}}{d P_{\mathrm{i}}}, i=1 \ldots N\right) \\
\lambda^{\text {nax }} & =\max \left(\frac{d F_{\mathrm{i}}}{d P_{\mathrm{i}}}, i=1 \ldots N\right)
\end{aligned}
$$

Pada setiap iterasi hitung nilai total biaya dan total daya yang dibangkitkan oleh semua unit. Hal itu akan merepresentasikan setiap titik untuk membentuk kurva Fs (Ps )

\section{ECONOMIC DAN EMISSION DISPATCH}

\section{A. Emission Dispatch}

Pada setiap operasi sistem tenaga listrik ada dua hal yang perlu diperhatikan yaitu, biaya pembangkitan dan emisi gas buang dari masing masing unit pembangkit. Bebrapa pembangkit listrik yang menggunakan bahan bakar fosil akan menghasilkan emisi dari sisa pembakaran. Emisi tersebut dapat berupa Sulfur Dioksida (SO2), Karbon Dioksida (CO2), dan Nitrogen Oksida (NOx).

$$
E(P)=\sum_{i=1}^{N} 10^{-2}\left(\alpha_{i}+\beta_{i} P_{i}+\gamma_{i} P_{i}^{2}\right)+\zeta_{\mathrm{j}} \exp \left(\lambda_{i} P_{i}\right)
$$

Dimana $\mathrm{E}(\mathrm{P})$ adalah total emisi generator dalam $\mathrm{g}$ dan $\alpha \mathrm{i}, \beta \mathrm{i}$, $\gamma \mathrm{i}, \zeta \mathrm{i}$, dan $\lambda \mathrm{i}$ adalah koefisien non-negatif dari karakteristik emisi generator unit-i.

\section{B. Economic Dispatch}

Economic dispatch merupakan salah satu masalah yang harus diselesaikan dalam operasi system tenaga listrik. Economic dispatch didefinisikan sebagai proses pengalokasian daya pembangkitan kepada generator sehingga sistem pada beban dapat disuplai secara ekonomis [5]. Tujuan utama dari economic dispatch adalah bagaimana mengoperasikan sistem tenaga untuk menyuplai semua beban dengan biaya minimum dan dapat memenuhi permintaan beban dengan biaya operasi sekecil mungkin. Terdapat berbagai macam metode untuk 
menyelesaikan permasalahan economic dispatch, mulai dari metode sederhana sederhana seperti iterasi lamda, base point, participation factors dan metode gradient hingga menggunakan firefly algorithm, Artificial bee colony (ABC), dan Particle swarm optimization algorithm (PSO) [6].

$$
F_{\tau}=\sum_{i=1}^{\mathrm{n}} F_{i}\left(P_{i}\right)
$$

Dimana Ft adalah total biaya dalam R/h, i merupakan jumlah dari generator, $P_{-} i$ adalah daya generator ke i yang dinyatakan dalam MW. Sementara Fi (Pi) merupakan biaya pembangkitan untuk Pi.

\section{Constraints}

Terdapat beberapa hal yang perlu diperhatikan saat melakukan economic dispatch, salah satunya adalah permintaan beban (load). Total daya yang dibangkitkan oleh suatu generator harus sama dengan permintaan beban ditambah losses.

$$
\begin{gathered}
P_{D}+P_{2}-\sum_{i=1}^{\mathrm{n}} F_{i}\left(P_{i}\right)=0 \\
\sum_{i=1}^{\mathrm{n}} F_{i}\left(P_{i}\right)=P_{D}+P_{2}
\end{gathered}
$$

Dimana P_D merupakan total permintaan beban dan P_L adalah losses pada saluran transmisi.

Daya yang dibangkitkan oleh generator harus berada diantara ratingnya (Pmin dan Pmax). Batasan pada setiap generator dapat dituliskan:

$$
P_{i, \text { trin }} \leq P_{i} \leq P_{i, \operatorname{tnax}}
$$

Dimana $P_{-}(i, m i n)$ adalah daya output minimum dari generator i dan $P_{-}(i, \max )$ merupakan daya output maksimum dari generator $\mathrm{i}$.

\section{PENERAPAN CUCKOO SEARCH ALGORITHM}

Cuckoo search algorithm merupakan metode berbasis populasi yang sama dengan metode meta-heuristik lainnya. Struktur dari algoritma ini terdiri dari dua operasi utama yaitu pencarian langsung yang didasari levy flight dan pencarian acak yang didasari oleh probabilitas induk burung lain menemukan telur asing di sarangnya. Dengan kombinasi dari dua operasi, algoritma cuckoo search menjadi metode pencarian yang lebih baik dibandingkan metode meta-heuristik lainnya.

Pada cuckoo search, setiap sarang merepresentasikan solusi dan populasi dari sarang digunakan untuk mencari solusi terbaik dari permasalahan. Langkah-langkah dasar dari metode cuckoo search ini dijelaskan sebagai berikut :

Berdasarkan data SPP maka dapat dihitung sudut perlindungannya sebagai berikut.
Step $1:$ Inisialisasi

Populasi dari Np sarang burung lain direpresentasikan oleh $X=\left[X_{1}, X_{2}, \ldots, X_{N P}\right]^{\tau} \quad$ dimana setiap sarang $X_{i}=\left[P_{i 1}, P_{i 2}, \ldots, P_{i j}, \ldots, P_{i N}\right]$

Merepresentasikan daya keluaran setiap unit. Daya keluaran setiap unit diinisiasikan oleh $P_{j}^{\text {tnit }}+\operatorname{ran} d_{1} *\left(P_{j}^{\text {nax }}-P_{j}^{\text {tnir }}\right)$ dimana ran $\dot{\alpha}_{1}$ merupakan distribusi acak antara 0 dan 1 .

\section{Step 2 : Pencarian sarang}

Pada proses pencarian sarang, sejumlah sarang dari burung cuckoo yang ada akan dipilih secara random, dimana sarang yang terpilih tidak boleh sarang yang terbaik, hal ini disebabkan karena sarang yang terbaik akan digunakan dalam proses perhitungan. Pada sarang yang terpilih ini kemudian akan dilakukan perhitungan terhadap matriks fuzzy yang terdapat di dalamnya. Proses perhitungan dapat dijabarkan sebagai berikut:

$$
A 1=A+\text { stepsize }
$$

dimana A menyatakan matriks fuzzy lama untuk sarang yang terpilih, A1 menyatakan matriks fuzzy baru untuk sarang yang terpilih dan stepsize menyatakan besar randomstep yang menggunakan formula sebagai berikut:

$$
\text { stepsize }=0.01 * \text { step } *(s-\text { best })
$$

dimana 0.01 menyatakan hasil perhitungan Lévy Flights dengan algoritmamantegna. s menyatakan matriks fuzzy lama untuk sarang yang terpilih dan best menyatakan matriks fuzzy dari sarang yang terbaik. Untuk proses perhitungan lévy flights dengan algoritma mantegna dapat dijabarkan sebagai berikut.

1. Dilakukan perhitungan terhadap besar langkah step menggunakan rumus :

$$
\text { step }=\frac{u}{|v| 1 / \beta}
$$

Dimana u dan v merupakan nilai yang diambil dari distribusi normal.

2. Masukkan nilai $\sigma_{u}=\left\{\frac{\tau(1+\beta) \operatorname{xin}\left(\frac{\pi \sigma}{2}\right)}{\tau\left|\frac{1+\theta}{2}\right| \beta, 2 \frac{0-1}{2}}\right\}^{1 / \beta}$ dan $\sigma_{v}=1$

Dimana $\tau$ menyatakan fungsi distribusi gamma (menggunakan fungsi dari library matematika bawaan) dan $\beta$ menyatakan nilai konstanta perhitungan, dalam hal ini nilai yang digunakan adalah $3 / 2$

Step 3 : Kemungkinan penemuan telur asing

Sebuah tindakan penemuan telur asing di sarang tuan rumah dengan probabilitas Pa juga menciptakan sebuah solusi baru untuk permasalahan serupa untuk levy flight. Solusi baru karena penemuan telur asing dapat dilakukan dengan cara :

$$
X_{i}^{d i s}=x_{b e s} t_{i}+K \times \Delta X_{i}^{d i s}
$$


Dimana $\mathrm{K}$ merupakan koefisien baru yang ditentukan berdasarkan probabilitas burung lain menemukan telur asing pada sarangnya :

$$
K \begin{cases}1 & \text { if rand } \\ 0 & \text { otherwise }\end{cases}
$$

\section{SIMULASI DAN ANALISIS}

\section{A. Hasil Composite Generation Cost Function}

Tabel 1 merupakan persamaan baru untuk masing-masing bus pada sistem $500 \mathrm{kV}$ Jawa-Bali. Tabel 2 merupakan persamaan untuk pembangkit hidro pada system 500kV JawaBali. Persamaan tersebut nantinya akan digunakan untuk melakukan economic dispatch. Sementara Tabel 3 merupakan persamaan emisi untuk masing-masing pembangkit yang nantinya akan digunakan untuk melakukan emission dispatch.

Tabel 1.

Persamaan Biaya Pembangkit Setelah Dikomposit

\begin{tabular}{lccccc}
\hline \hline Pembangkit & $\mathbf{x 2}$ & $\mathbf{x 1}$ & $\mathbf{x 0}$ & Pmin & Pmax \\
\hline Suralaya & -9.16689 & 413479.4 & 40667795 & 1703 & 3247 \\
Paiton & -49.9043 & 577947.3 & -14774223 & 1954 & 2900 \\
Muara Tawar & -696.988 & 3937191 & $-2.56 \mathrm{E}+09$ & 1401 & 2955 \\
Gresik & 137.251 & 1254309.5 & 10961381 & 529 & 955 \\
Tanjung Jati & 3.37162 & 284810.3 & 55581457 & 1221 & 1979 \\
Grati & 1412.58 & 1018922 & 57269598 & 320 & 795.6 \\
\hline \hline
\end{tabular}

Tabel 2. Incremental Cost Rate PLTA

\begin{tabular}{lccccc}
\hline \hline Pembangkit & $\mathbf{x 2}$ & $\mathbf{x 1}$ & $\mathbf{x 0}$ & Pmin & Pmax \\
\hline Cirata & 0 & 12000 & 0 & 500 & 1000 \\
Saguling & 0 & 8000 & 0 & 350 & 700 \\
\hline \hline
\end{tabular}

Tabel 3.

Nilai Persamaan Emisi Tiap Unit Pembangkit

\begin{tabular}{lccccc}
\hline \hline Pembangkit & $\boldsymbol{\gamma}$ & $\boldsymbol{\beta}$ & $\boldsymbol{\alpha}$ & Pmin & Pmax \\
\hline Suralaya & -0.1145 & 5164.84 & 507988.6 & 1703 & 3247 \\
Paiton & -0.696 & 8060.68 & -2060575.21 & 1954 & 2900 \\
Muara Tawar & -1.595 & 9015.56 & -5873535.42 & 1401 & 2955 \\
Gresik & 0.3877 & 3543.443 & 309660.6 & 529 & 955 \\
Tanjung Jati & 0.0418 & 3536.53 & 690164.34 & 1221 & 1979 \\
Grati & 8.0238 & 5787.71 & 3253048.75 & 320 & 795.6 \\
\hline \hline
\end{tabular}

\section{B. Economic dan Emission Dispatch}

Tabel 4 merupakan hasil simulasi menggunakan metode optimasi cuckoo search yang berisi daya yang terbangkit oleh setiap unit pembangkit dan biaya masing-masing pembangkit. Sementara tabel 5 menunjukkan total daya yang dibangkitkan, biaya total yang diperlukan untuk memenuhi permintaan beban dan total emisi yang dihasilkan.
Tabel 4.

Hasil Simulasi Economic Dispatch Menggunakan Cuckoo Search

\begin{tabular}{lcr}
\hline \hline \multicolumn{1}{c}{ Pembangkit } & Daya (MW) & Cost (Rp/Jam) \\
\hline Suralaya & 2886.4689 & 1157787528 \\
Paiton & 2601.8766 & 1018165109 \\
Muara Tawar & 1569.1263 & 1896820959 \\
Gresik & 732.70698 & 1102339700 \\
Tanjung Jati & 1859.272 & 596776723.5 \\
Grati & 329.11998 & 1061054967 \\
Cirata & 827.19356 & 9926322.688 \\
Saguling & 557.63568 & 4461085.448 \\
\hline \hline
\end{tabular}

Tabel 5.

Total Daya, Biaya dan Emisi

\begin{tabular}{ccc}
\hline \hline Daya (MW) & Cost (Rp/Jam) & Emisi (gram/Jam) \\
\hline 11363.4 & 6847332395 & 52241497.24 \\
\hline \hline
\end{tabular}

Dari hasil simulasi didapatkan nilai daya yang akan dibangkitkan oleh setiap generator untuk memnuhi permintaan beban, dimana daya yang akan dibangkitkan oleh setiap unit berbeda beda. Untuk permintaan beban sebesar 11363.4 MW, unit Suralaya harus menyuplai daya sebesar 2886.46 MW, unit Paiton sebesar 2601.87 MW, unit Muara Tawar sebesar 1569.12 MW, unit Gresik sebesar 732.7 MW, unit Tanjung Jati sebesar 1859.27 MW dan unit Grati 329.11 MW. Sementara untuk pembangkit hidro, unit Cirata membangkitkan daya sebesar 827.19 MW dan unit Saguling sebesar 557.63 MW. Nilai tersebut sudah sesuai dengan batasan daya minimum dan maksimum pada masing-masing pembangkit. Biaya total yang diperlukan pembangkit berdasarkan simulasi menggunakan metode cuckoo search sebesar 6,847,332,395 Rp/jam. Sedangkan total emisi dari hasil pembakaran adalah 52,241,497.24 gram/jam.

\section{Validasi Data}

Quadratic Programming akan digunakan sebagai metode pembanding dari hasil simulasi yang didapat. Quadratic programming merupakan metode yang digunakan untuk menyelesaikan permasalahan optimasi dengan fungsi objektif berupa persamaan kuadrat dan batasan batasan linear.

Tabel 6.

Perbandingan Hasil Quadratic Programming dan Cuckoo Search Untuk Permasalahan Economic Dispatch

\begin{tabular}{|c|c|}
\hline Q Quadratic Programming & Cuckoo Search \\
\hline 10749972892 & 11299382723 \\
\hline \multicolumn{2}{|c|}{$\begin{array}{c}\text { Tabel } 7 . \\
\text { Persamaan Biaya Pembangkit Setelah Dikomposit }\end{array}$} \\
\hline Quadratic Programming & "Cuckoo Search \\
\hline 70819523.41 & 72668689.93 \\
\hline
\end{tabular}

Dari tabel 6 dan 7 terlihat perbandingan antara quadratic programming dan cuckoo search untuk permasalahan economic dan emission dispatch. Terdapat sedikit perbedaan 
nilai dari kedua metode tersebut sehingga metode yang digunakan pada tugas akhir ini dapat diterapkan untuk permasalahan economic dan emission dispatch

\section{Analisis Statistik Fitness}

Tabel 8.

Persamaan Biaya Pembangkit Setelah Dikomposit

\begin{tabular}{cc}
\hline \hline Tes & Fitness \\
\hline 1 & 6.8 \\
2 & 6.85 \\
3 & 6.96 \\
4 & 6.85 \\
5 & 6.78 \\
6 & 6.92 \\
7 & 7 \\
8 & 6.73 \\
9 & 6.69 \\
10 & 6.93 \\
Min & 6.73 \\
Max & 7 \\
Mean & 6.85 \\
SDV & 0.1018113 \\
\hline \hline
\end{tabular}

Tabel 8 menunjukkan nilai minimum, maksimum, rata-rata, dan standar deviasi dari fitness. Nilai standar deviasi yang kecil menunjukkan nilai-nilai pada tabel berkumpul disekitar rata-rata hitungannya (penyebarannya kecil).

\section{PENUTUP}

\section{A. Kesimpulan}

Dari simulasi yang diperoleh didapatkan kesimpulan sebagai berikut :

1. Algoritma CSA dapat digunakan untuk melakukan economic maupun emission dispatch.

2. Pengkompositan persamaan generator akan mempermudah proses optimasi.

3. Pemaksimalan pengoperasian unit pembangkit dipengaruhi biaya operasi tiap unit pembangkit yang berbeda beda.

4. Total biaya yang diperlukan untuk memenuhi permintaan beban adalanh sebesar 6,847,332,395 Rp/jam

5. Total emisi yang dihasilkan oleh pembangkit adalah sebesar 52,241,497.24 gram/jam

6. Hasil analisis statistic menunjukkan nilai penyebaran fitness kecil.

B. Saran

Dari studi yang telah dilakukan diperoleh beberapa rekomendasi, yaitu:

1. Kasus yang digunakan dapat dikembangkan.

2. Losses pada saluran transmisi dapat diperhitungkan

3. Pengoptimasian economic dan emission dispatch dapat menambahkan batasan lain.

\section{DAFTAR PUSTAKA}

[1] Chapman, Stephen J., "Electric Machinery Fundamentals", McGrawHill, 2005.

[2] Saadat, Hadi, "Power System Analysis", McGraw-Hill, 1999.

[3] PT. PLN (Persero) P3B APB Gandul

[4] Marsudi, Djiteng, "Operasi Sistem Tenaga Listrik", Graha Ilmu, Yogyakarta, 2006.

[5] Chowdhury, B.H. dan Rahman, Saifur, "A Review of Recent Advances in Economic Dispatch," IEEE Transactions on Power Systems, Vol. 5, No. 4, November 1990

[6] K., Thenmalar dan Allirani, A., "Solution of Firefly Algorithm for the Economic Thermal Power Dispatch with Emission Constraint in Various Generation Plants," Tiruchengode, India, July 4 - 6, 2013. 